NASA Technical Memorandum 105254

AIAA-91-2792

$\rho \cdot 12$

\title{
Application of an Integrated Flight/ \\ Propulsion Control Design \\ Methodology to a \\ STOVL Aircraft
}

Sanjay Garg

National Aeronautics and Space Administration

Lewis Research Center

Cleveland, Ohio

and

Duane L. Mattern

Sverdrup Technology, Inc.

Lewis Research Center Group

Brook Park, Ohio

Prepared for the

Guidance, Navigation and Control Conference

sponsored by the American Institute of Aeronautics and Astronautics

New Orleans, Louisiana, August 12-14, 1991 



\section{APPLICATION OF AN INTEGRATED FLIGHT/PROPULSION CONTROL}

\section{DESIGN METHODOLOGY TO A STOVL AIRCRAFT}

\author{
Sinjay Garg \\ National Aeronautics and Space Administration \\ Lewis Research Center \\ Clevelend, Ohio 44135
}

and

Abstract

Results are presented from the application of an emerging Integrated Flight/Propulsion Control (IFPC) design methodology to a Short Take-Off and Vertical Landing (STOVL) aircraft in transition flight. The steps in the methodology consist of designing a centralized controller, partitioning the centralized controller into separate subsystem controllers and designing command shaping prefilters to provide the overall desired response to pilot command inputs. A previously designed centralized controller is first validated for the integrated airframe/engine plant used in this study. This integrated plant is derived from a different model of the engine subsystem than the one used for the centralized controller design. The centralized controller is then partitioned in a decentralized, hierarchical structure comprising of airframe lateral and longitudinal subcontrollers and an engine subcontroller. Command shaping prefilters from the pilot control effector inputs are then designed and time histories of the closed-10op IFPC system response to simulated pilot commands are compared to desired responses based on handling qualities requirements. Finally, the propulsion system safety and nonlinear limit protection logic is "wrapped" around the engine subcontroller and the response of the closed-loop integrated system is evaluated for transients that encounter the propulsion surge margin limit.

\section{Introduction}

The trend in future military fighter/tactical aircraft design is towards aircraft with new/enhanced maneuver capabilities such as Short Take-Off and Vertical Landing (STOVL) and high angle of attack performance. An integrated flight/propulsion control (IFPC) system is required in order to obtain these enhanced capabilities with reasonable pilot workload. An integrated approach to control design is then necessary to achieve an effective IF PC system. Such a design approach is currently being developed at NASA Lexis Research Center as part of an ongoing STOVL controls research program. This methodology is referred to as IMPAC - Integrated Methodology for Propulsion and Airframe Control [1]. The significant features of the IMPAC methodology are the design of a centralized controller considering the airframe and propulsion systems as one integrated system and the partitioning of the centralized controller into decentralized subsystem controllers for state-of-the-art IFPC implementation. Here partitioning means representing the high-order centralized controller with two or more lower order subcontrollers which approximate the input/output behavior of the centralized controller. The centralized control design accounts for all the subsystem interactions in the design stage and the partitioning results in easy to implement subcontrollers that allow for independent subsystem validation. The entire IMPAC methodology is presented in detail in Ref. [1]. A flowchart of the methodology is shown in Fig. 1 with the numbered blocks indicating the major steps in the methodology. The IMPAC design approsch evolved from an evaluation of the two IFPC design methodologies that were developed under an Air Force sponsored program called Design Methods for Integrated Control Systems (DMICS) $([2,3])$. The IMPAC methodology strives to combine the best aspects of the two DMICS methodologies.

The overall structure for the linear control design portion of IMPAC (corresponding to Blocks 2 and 3 in Fig. 1) is show $n$ in Fig. 2. The steps in the linear control design are: (1) Design of a centralized feedback controller to provide command tracking and stability and performance provide command tracking and se fully integrated irframe/propuision model as one high-order system; (2) Partition of the centralized controller into a decentralized, hierarchical form compatible with implementation requirements; and (3) Design of command shaping prefilters from pilot control effectors to commanded variables to provide the overall desired response to pilot inputs. In this paper, results are presented from the application of these steps of the methodology to IFPC design for a linear integrated airframe/propulsion model of a STOVL aircraft in transition flight to demonstrate the design steps. The centralized controller used in this study was designed previously in Ref. [4] and the details of the centralized control design step are discussed in that reference. So only those features of the centralized control design step which are relevant for a thorough understanding of the overall IFPC design and evaluation results are presented bere. Also presented in this paper are some preliminary results from the evaluation of the linear control design in the presence of the propulsion system operating schedules and the propulsion system nonlinearities due to safety and limit protection logic.

In the following sections, a brief description of the vehicle models to be used for control design and evaluation is first presented. The application of the three steps in the linear control design process is then discussed for the vehicle model under study and intermediate design results are presented. The complete point control design with the propulsion system operating schedule and limit protection logic included is then evaluated for sample pilot control inputs and the response is compared with that of an "ideal response model" which is derived from Level I handling qualities requirements.

The vehicle considered in this study is representative of the delta winged E-7D supersonic STOVL aiffame powered by a high bypass turbofan engine [5]. The aircraft is equipped with the following control effectors: ejectors to provide propulsive lift at low speeds and hover; a $2 D-C D$ vectoring aft nozzle with afterburner for supersonic light; a vectoring ventral nozzle for pitch control and lift augmentation during transition; and jet reaction control systems (RCS) for pitch, roll and yaw control during transition and hover. A schematic diagram of the aircraft with relative location of the various control effectors mentioned above is shown in Fig. 3 . 


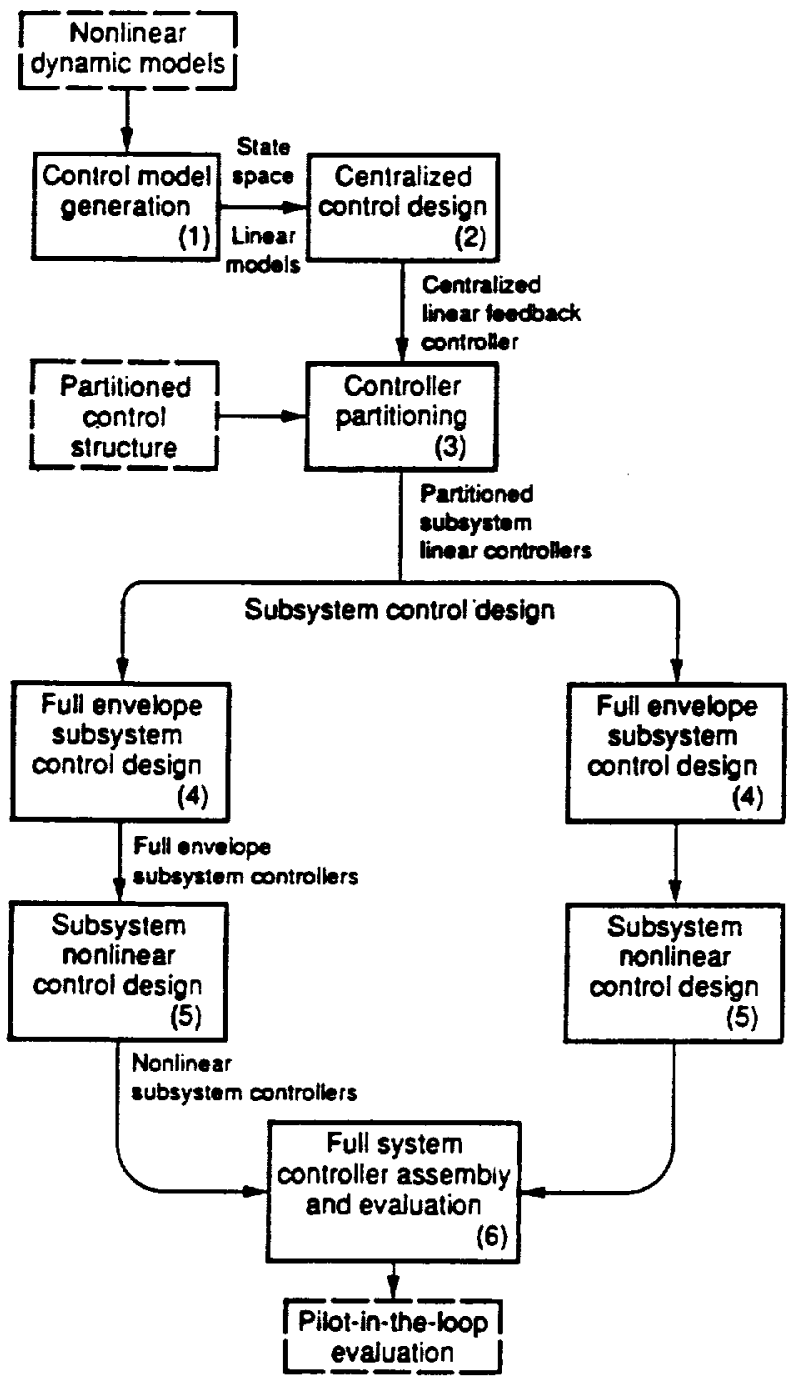

Figure 1. IMPAC Methodology Flowchart

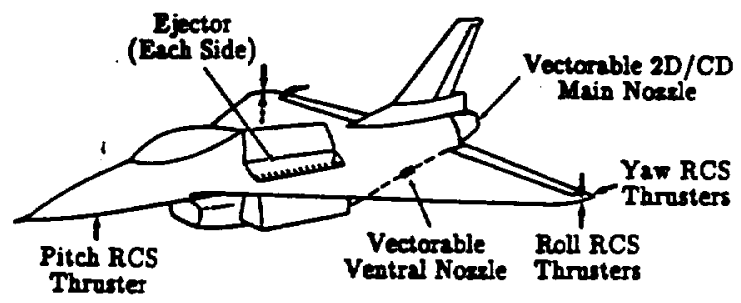

Figare 3. Control Effecton for E-7D Aircreft

Engine compressor bleed Alow is used for the RCS thrusters and the mixed engine flow is used as the primary ejector flow. Detailed ducting diagrams of the engine and discussion of the ejector STOVL concept are arailable in Ref. [6].

The procedure for generating linear integrated airframe/engine models for control design and evaluation from the ceparate nonlinear airrame and propulsion orotem simulations is discussed in Ref. [5]. The integrated linear design model used in this study is of the form

$$
\dot{\bar{x}}=A \bar{x}+B \bar{u} ; \bar{y}=C \bar{x}+D \bar{u}
$$

where the otate vector is

$$
\begin{aligned}
& \bar{x}=[u, v, w, p, q, r, \phi, \theta, N 2, N 25, \\
& \text { Tmhpc, Tmpc,Tmhpt,Tmlpt] }{ }^{T} \\
& \text { with } \\
& \begin{array}{l}
\mathrm{u} \quad=\text { Axial Velocity, } \mathrm{ft} / \mathrm{s} \\
\mathbf{v} \quad=\text { Lateral Velocity, } \mathrm{ft} / \mathrm{s}
\end{array} \\
& \text { w } \quad=\text { Vertical Velocity, ft/s } \\
& \mathrm{p} \quad=\text { Roll Rate, } \mathrm{rad} / \mathrm{s} \\
& \text { q }=\text { Pitch Rate, rad } / 8 \\
& \mathrm{I} \quad=\text { Yaw Rate, } \mathrm{rad} / \mathrm{s} \\
& \phi \quad=\text { Roll Attitude, rad } \\
& \theta \quad=\text { Pitch Attitude, rad } \\
& \text { N2 = Engine Fan Speed, } \mathrm{rpm} \\
& \text { N25 = High Pressure Compressor Speed, rpm } \\
& \text { Tmbpc }=\text { High Press. Compressor Metal Temp., }{ }^{\circ} R \\
& \text { Tmpc = Burner Metd Temp., }{ }^{\circ} \\
& \text { Tmhpt }=\text { High Pressure Turbine Metal Temp., }{ }^{\circ} R \\
& T m p t=\text { Low Pressure Turbine Metal Temp., }{ }^{\circ} \text {. }
\end{aligned}
$$

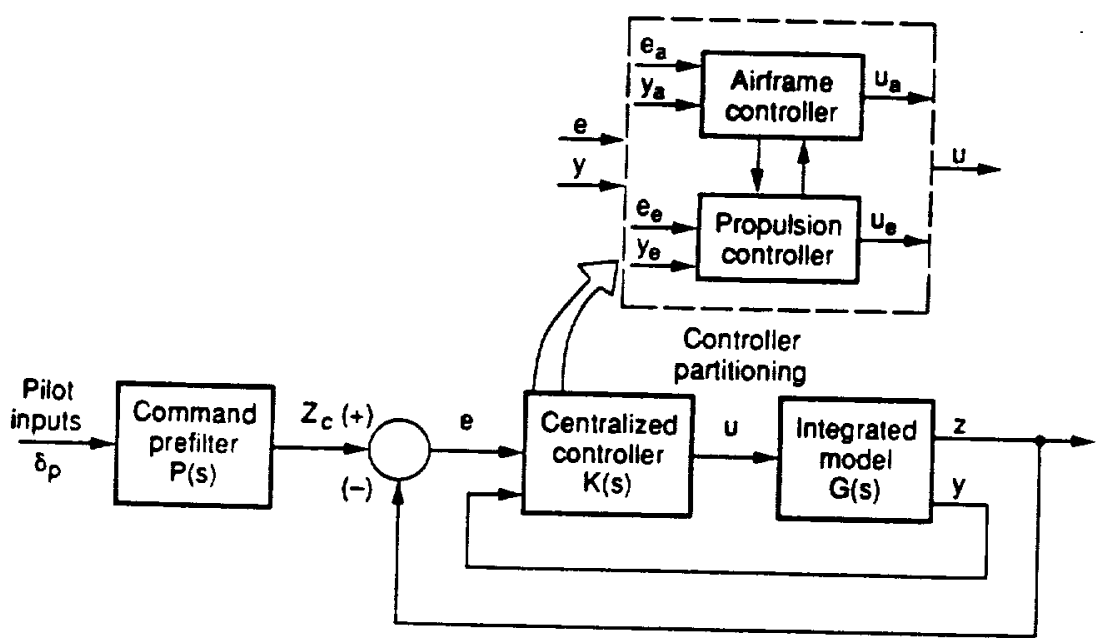

Figure 2. Block Diagram for Linear Control Design Portion of IMPAC 
The control inputs are

$$
\begin{array}{r}
\bar{u}=[8 e, \delta a, \delta r, A Q R, A Y R, A R R, \\
\text { WF,A8,ETA,A78,ANG79,ANG8 }]^{T}
\end{array}
$$

with

$$
\text { Se } \quad=\text { Elevator Deflection, } \operatorname{deg}
$$$$
\delta \text { = Aileron Deflection, deg }
$$$$
\text { or } \quad=\text { Rudder Dellection, deg }
$$$$
\mathrm{AQR}=\text { Pitch RCS Area, in }{ }^{2}
$$$$
\text { AYR = Yaw RCS Area, in }{ }^{2}
$$$$
\text { ARR }=\text { Roll RCS Area, in }{ }^{2}
$$$$
\mathrm{WF}=\text { Fuel Flow Rate, } \mathrm{lbm} / \mathrm{hr}
$$$$
\text { A8 }=\text { Aft Nozzle Throat Area, in }{ }^{2}
$$$$
\text { ETA = Ejector Butterly Angle, deg }
$$

A78 $=$ Ventral Nozzle Area, in ${ }^{2}$

ANG79= Ventral Nozzle Vectoring Angle, deg

ANG8 = Aft Nozzle Vectoring Angle, deg.

The model outputs are

$$
\begin{aligned}
& \bar{y}=[V, V, \theta, q, \gamma, \phi, p, \beta, r, \\
&\text { N2, } \beta, F G 9, F G E, F G V]^{T} \\
& \text { with } \quad=\text { True Airspeed, } \mathrm{ft} / \mathrm{s} \\
& \mathrm{V} \quad=\text { Total Acceleration, } \mathrm{ft} / \mathrm{s}^{2} \\
& \gamma \quad=\text { Longitudinal Flight Path Angle, deg } \\
& \gamma=\text { Sideslip Angle, deg } \\
& \beta=\text { Rate of change of Sideslip Angle, deg/s } \\
& \beta=\text { Aft Nozzle Gross Thrust, lbs } \\
& \text { FGg }=\text { Total Ejector Gross Thrust, lbs } \\
& \text { FGE }=\text { Ventral Nozzle Gross Thrust. }
\end{aligned}
$$

The other outputs are as discussed under state description except that the angular positions and rates are in degrees. The current study did not include actuator and sensor dynamics. These dynamics and the estimators for the three thrusts will be included in future nonlinear control evaluation work

The propulsion system state variables described above differ from those used in the integrated models of the previous studies (Refs. $[4,5]$ ). The propulsion system linear models used in the previous studies were derived from a cetailed non-realtime aero-thermo cycle-deck simulation of the turbofan engine. The propulsion system models used in this study are derived from a simplified real-time Component Level Model simulation of the turbofan engine. During preliminary IFPC design studies for the E-7D aircraft, some discrepancies were noted in the transient and steady-state gross thrust and fan speed response between the CLM and the detailed cycle-deck simulations. Since the CLM simulation is to be used in the piloted evaluation of the control augmented aircraft because of its realtime execution capability, it was decided to use the CLM based linear models for further control design and evaluation

Several of the control inputs $\bar{u}$, listed above in (3), include blending of the actual aircraft control effectors. For instance, only $3 \mathrm{RCS}$ areas, AQR, AYR and ARR, are used in the linear design model whereas the full nonlinear model has 5 controlled RCS areas. The reasons for this are that the nose pitch RCS and the two yaw RCS thrusters provide thrust in only one direction as shown in Fig. 3, and the wing tip roll RCS thrusters are to be used differentially for roll control and collectively for pitch control. Since yau RCS thrusters provide only forward thrust, left yaw RCS is used for right yaw and right yaw RCS is used for left yaw in the nonlinear model. Using both left and right yau RCS areas in the design model can tes ult in a control design that uses the two areas differentially to enhance yaw control which will be consistent with the actual implementation. Details of control blending for other control effectors based on open-loop control effectiveness studies and designers' knowledge of system dynamics are discussed in Ref. [4].

Note that there is an absolute nonlinearity in the relationship from commanded RCS areas to compressor bleed flow demand in that although the RCS area may be positive or negative depending on the desired direction of RCS thrust, the compressor bleed flow demand (WB3) to generate the thrust is always positive. For a linear model trimmed about zero RCS areas, this relationship is of the form WB3 $i=K_{j}|A i R|$ where WB3i is the demanded bleed tow due to $A$ iR command with i representing $Q, Y$ or $R$ for pitch, $y a w$ or roll $R C S$, respectively, $K_{i}$ is as appropriate constant and $|\cdot|$ represents absolute value. All the results presented in this paper include the ARCS to WB3 nonlinearity in the closed-loop evaluation system. The flight phase considered in this study is the decelerating transition during approsch to hover landing. During this light phase, the control of the aircraft is transitioning from aerodynamic control surfaces to propulsion system generated forces and moments. For this study, the linear design model was obtained for a steady-itate level light at a trim speed of $V_{0}=80$ Knots and a trim flight path angle of $\gamma_{0}=-3$ deg, with propulsive lift supporting spproximately $60 \%$ of the aircraft weight and with adequate distribution between ejector and ventral nozzle thrust to provide pitch trim. Although the airspeed span for transition flight phase is from 120 Knots to 50 Knots, open-loop analyses indicated that the BO Knot model provides a "good average" of the dynamic behavior of the aircraft in transition flight. Thus the 80 Knot integrated model is used as the nominal control design model. Eigenvalue analysis of the design model indicated an unstable short period mode at $\lambda=1.3$.

\section{Centralized Control Design}

\section{Control Design}

Recent advances in $H$ control theory [8] and computational algorithms to solve for $B_{\phi}$ optimal control laws [9] have made this theory a viable candidate to be applied to complex multivariable control design problems. In general terms, this technique provides the designer the means to synthesize a controller for "best" guaranteed performance in the presence of "worst case" disturbance (or command). Proper formulation of the control design problem using $\mathrm{B}_{-}$theory provides for building in stability robustness and obtaining an adequate trade-off between performance and allowable control power in the resulting controller. The results of the preliminary application of $H_{\infty}$ control design techniques to IFPC design for the E-7D STOVL aircraft, reported in Refs. $[4,5]$, have been very encouraging. So the $E$ control synthesis technique is being used for the centralized control design portion of IMPAC

As mentioned earlier, a centralized IFPC design was presented in Ref. [4] for the E-7D transition phase integrated model with the propulsion linear model derived from the detailed cycle deck simulation. Detailed robustness analyses [4] showed that this controller provides closed-loop system robustness for large variations in the engine rotor dynamics and rotor speeds (N2, N25) response to fuel fow (WF) input. Since the main difference between the integrated model being used in this study and that used previously is that the CLM based engine model has slower rotor dynamic response, it was decided to first investigate whether the previously designed controller will provide adequate performance for the integrated mode] being used in this study. Fig. 4 shows an example result of closed-loop system evaluation using this 14th order 
centralized controller on the CLM based integrated design model. The open-loop fan speed response to a step fuel flow input of WF $=100 \mathrm{lbm} / \mathrm{hr}$ is compared in Fig. 4(a) for the detailed cycle-deck and CLM based linear propulsion models corresponding to the $\mathbf{8 0}$ Knot trim condition, and the closed-loop fan speed response and fuel flow requirements for a step tan speed command of $200 \mathrm{rpm}$, using the centralized controller, are compared in Figs. 4(b) and (c), respectively. From Fig. $4(a)$ we note that the CLM based model response is slower, with a $10 \%$ increase in tr90 (90\% rise time) as compared to the cycle-deck based model, and the perturbation steady-state fan speed response is lower by $20 \%$. Fig. 4(b) shows that inspite of the differences in the open-loop model response, there are no noticeable differences in the closed-loop fan speed response. As is to be expected, Fig. 4(c) shows that the fuel flow requirement will be higher for the CLM based model in order to track the same fan speed command as with the cycle-deck based model. The comparison between the CLM based integrated model and the cycle-deck model for closed loop response to step commands in other controlled variables using this centralized controller was equally as good as the fan-speed response comparison. Therefore it was decided to use this controller as the centralized controller for the current IFPC design. Although the centralized controller is discussed in detail in Ref. [4], some information on the control design philosophy and the controller structure is presented in the following to assist in understanding the controller partitioning and prefilter design steps.

The centralized controller structure is consistent with that shown in Fig. 2 with the controlled variables $\bar{z}$ selected to be

$$
\bar{z}=[\mathrm{Vv}, \mathrm{Qv}, \gamma, \mathrm{Pv}, \beta, \mathrm{N} 2]^{\mathrm{T}}
$$

with $V v=V+0.1 V, Q v=q+0.3 \theta, \quad P v=p+0.1 \phi$ and the others as discussed under plant outputs. The controller inputs are the tracking errors $\overline{\mathrm{e}}=\overline{\mathrm{z}}_{\mathrm{c}}-\overline{\mathrm{z}}$, the plant outputs $\bar{y}$ as in (4) but without the gross thrust (FG9, FGE and FGV) measurements, and with the RCS bleed flow demand WB3. The blending of controlled variables as in (6) was chosen to provide the response types that are desirable for good handling qualities $(10,11]$ in transition flight. The choice of $\mathrm{Vv}$ corresponds to designing an acceleration command system with velocity hold, and the choice of $\mathrm{Qv}$ and $\mathrm{Pv}$ correspond to designing a rate command-attitude hold system.

The centralized controller provided decoupled command tracking of the controlled variables $\bar{z}$ up to the desired bandwidth for each individual controlled variable

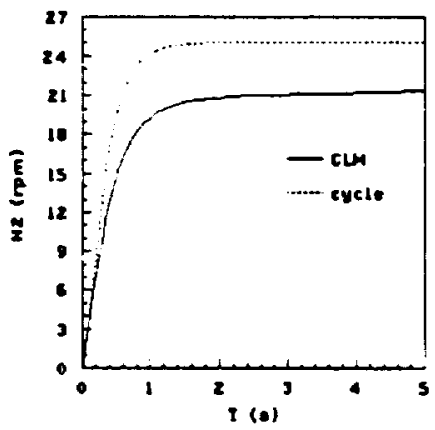

(a) Open-Loop Fan Speed (N2) Response to Step Fuel Flow $\mathrm{W} F=100 \mathrm{lbm} / \mathrm{hr}$ for Cycle-Deck and CLM Based Propulsion in the presence of the RCS bleed flow nonlinesrity, discussed earlier. This type of closed-loop isstem provides independent control of acceleration, pitch, flight path angle, roll and sideslip from the various pilot control effectors such as stick, throttle and rudder pedals etc., thus reducing pilot workload, and also control of the propulsion system operating point (N2) independent of the aircraft motion. Independent control of roll (Pv) and sideslip angle $(\beta)$ will result in a control system that provides automatic turn coordination thu further redncing pilot workload.

\section{Controller Partitioning}

In an overall aircraft deaign, traditionally the engine manufacturer needs a eeparate engine controller to be able to independently perform extensive testing to assure an adequate design and engine integrity. Also the centralized IFPC controller might contain many feedback paths which are not desirable from practical implementation considerations. To address these diffculties, the ides of partitioning the centralized controller (Block 3 in Fig. 1) into teparate virframe and propulsion system subcontrollers was introduced in Ref. [2]. The desired structure of controller partitioning will depend on the coupling between the various subsystems and on practical considerations related to integration of the independently controlled subsystems. A decentralized, hierarchical control structure as hown in Fig. 5 was chosen for controller partitioning in IMPAC. In Fig. 5 , the cubscript "a" refers to aiframe quantities, " $e$ " refers to propulsion system quantities, and "c" refers to commands.

The intermediate variables, $\bar{z}_{e a}$, represent propulsion system quantities that affect the airfame, for example propulsive forces and moments. Fig. 5 is simplified in that only the feedback paths from the controlled ontput errors are shown. The controller partitioning problem can be stated as follows :

$$
\begin{gathered}
\text { "Givan: } \quad K(s) \text { s.t. } \bar{u}(s)=K(s) \cdot\left[\begin{array}{c}
\bar{e}(s) \\
\bar{y}(s)
\end{array}\right], \\
\text { where } \bar{u}=\left[\begin{array}{c}
\bar{u}_{a} \\
\bar{u}_{e}
\end{array}\right], \bar{e}=\left[\begin{array}{c}
\bar{e}_{a} \\
\bar{e}_{e}
\end{array}\right], \\
\text { and } \bar{y}=\left[\begin{array}{l}
\bar{y}_{a} \\
\bar{y}_{e}
\end{array}\right],
\end{gathered}
$$

and a particular set of $\bar{z}_{\text {ea' }}$,

Models

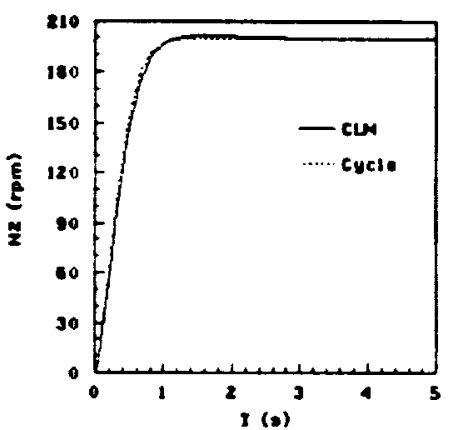

(b) Closed-Loop N2 Response to N2 Command

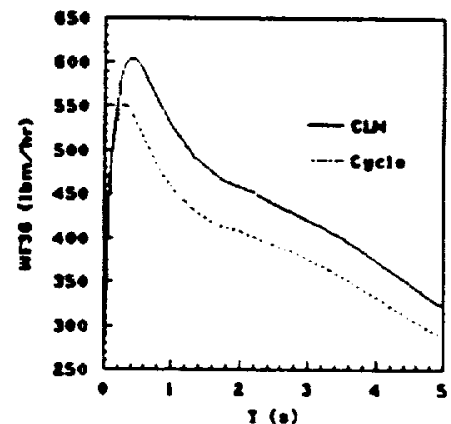

(c) Closed-Loop WF Requirement for N2 Command Tracking

Figure 4. Example Response with Centralized Controller of Ref. [4]. 
Find:

$$
\begin{aligned}
& K_{a}(s), K_{e}(s) \text { with } {\left[\begin{array}{l}
\bar{u}_{a}(s) \\
\bar{z}_{e a}(s)
\end{array}\right]=K_{a}(s) \cdot\left[\begin{array}{l}
\bar{e}_{a}(s) \\
\bar{y}_{a}(s)
\end{array}\right], } \\
& \text { and } \bar{u}_{e}(s)=K_{e}(s) \cdot\left[\begin{array}{c}
\bar{e}_{e}(s) \\
\bar{e}_{e a}(s) \\
\bar{y}_{e}(s)
\end{array}\right]
\end{aligned}
$$

So that: The closed-loop performance and robustness with the subcontrollers $K_{a}(s)$ and $K_{e}(s)$ match those with the centralized controller $K(s)$ to a desired accuracy. Furthermore the engine subcontroller should provide tracking of the interface variable commands, $\bar{z}_{e a}$ to allow for independent subsystem check-out.

A state-space parameter optimization based procedure to solve the above controller partitioning problem is currently being developed. Some preliminary results using this approach are available in Ref. [12]. The controller partitioning for this study was performed using straightforward steps, starting from the centralized controller, which exploit the designers' knowledge of the coupling between the airframe and propulsion system dynamics. The controller partitioning structure used for this study is shown in Fig. 6. The partitioning was done in two major steps: first the centralized controller was partitioned into decoupled lateral and longitudinal plus engine subcontrollers and then the longitudinal plus engine subcontroller was further partitioned into separate hierarchical longitudinal and engine subcontrollers. The detcled partitioning steps, discussed in the following, are: (1) Partitioning of centralized controller inputs and outputs into three input/output subsets corresponding to the lateral, longitudinal and engine subcontrollers; (2) Partitioning of the centralized controller into lateral and longitudinal-plus-engine subcontrollers; (3) Obtaining the $\bar{z}_{e}$ command tracking portion of the engine subcontroller from the longitudinal-plus-engine subcontroller; (4) Designing the $\bar{z}_{\text {ea }}$ command tracking portion of the engine subcontroller; (5) Obtaining the portion of the longitudinal subcontroller that approximates the desired $\bar{z}_{\text {ea }}$ response with the longitudinal-plus-engine subcontroller; and (6) Designing lead compensation for the longitudinal subcontroller portion of previous step to generate the $\bar{z}_{\text {ea }}$ command taking into account the finite $\bar{z}_{\text {ea }}$ tracking bandwidth. The emphasis in the controller partitioning presented herein is on matching the closed-loop performance with the centralized controller. The robustness of the closed-loop system with the partitioned controller has not been evaluated and will be addressed in the future.

\section{Step 1.}

The controller inputs $\bar{y}_{K}$, consisting of the tracking e:: 7 ss $\bar{e}$ and parts of the integrated plant outputs $\bar{y}$ as discussed earlier, and the controller outputs $\bar{u}$ were frst partitioned into three subsets corresponding to the lateral and longitudinal aircraft dynamics and the propulsion system dynamics. This partitioning of controller inputs and outputs is as follows:

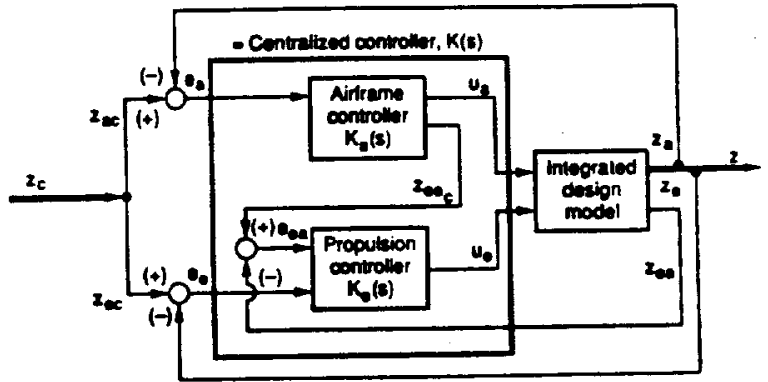

Figure 5. Simplified Block Diagram for Decentralized, Hierarchical Controller Partitioning

$$
\bar{y}_{K}=\left[\begin{array}{l}
\bar{y}_{\text {lat }} \\
\bar{y}_{\text {lon }} \\
\bar{y}_{\text {eng }}
\end{array}\right] \text { and } \bar{u}=\left[\begin{array}{l}
\bar{u}_{\text {lat }} \\
\bar{u}_{\text {lon }} \\
\bar{u}_{\text {eng }}
\end{array}\right] \text {. }
$$

with

$$
\begin{aligned}
& \bar{y}_{\text {lat }}=\left[e_{P_{v}}, e_{\beta}, \phi, p, \beta, r, \beta\right]^{T} \\
& \bar{y}_{\text {lon }}=\left[e_{V_{v}}, e_{Q v}, e_{\gamma}, V, V, \theta, q\right]^{T} \\
& \bar{y}_{\text {eng }}=\left[e_{N 2}, N 2, W B 3\right]^{T}
\end{aligned}
$$

and

$$
\begin{aligned}
& \bar{u}_{\text {lat }}=\left[\delta_{2}, \delta_{r}, \text { AYR,ARR }\right]^{T} \\
& \bar{u}_{\text {lon }}=\left[\delta_{e}, A Q R, A N G 79, A N G 8\right]^{T} \\
& \bar{u}_{\text {eng }}=[\text { WF,A8,ETA,A78 }]^{T}
\end{aligned}
$$

The rarious quantities in (7) and (8) above have been defined earlier under the vehicle model description. The nozzle vectoring angles, ANG79 and ANG8, were included as part of the longitudinal controls as these mainly affect the pitch dynamics of the sircraft and have very little effect on the propulsion system dynamics.

The interface from the propulsion system model to the airframe model was defined by the gross thrust from the three engine nozale systems - aft nozzle, ventral noxzle and the ejectors. Therefore, the intermediate variables $\bar{z}_{\mathrm{ea}}$ for hierarchical partitioning from the aiffame subcontroller to the engine subcontroller were chosen to be

$$
\overline{\mathbf{z}}_{\mathrm{ea}}=[\text { FG9,FGE,FGV }]^{\mathrm{T}}
$$
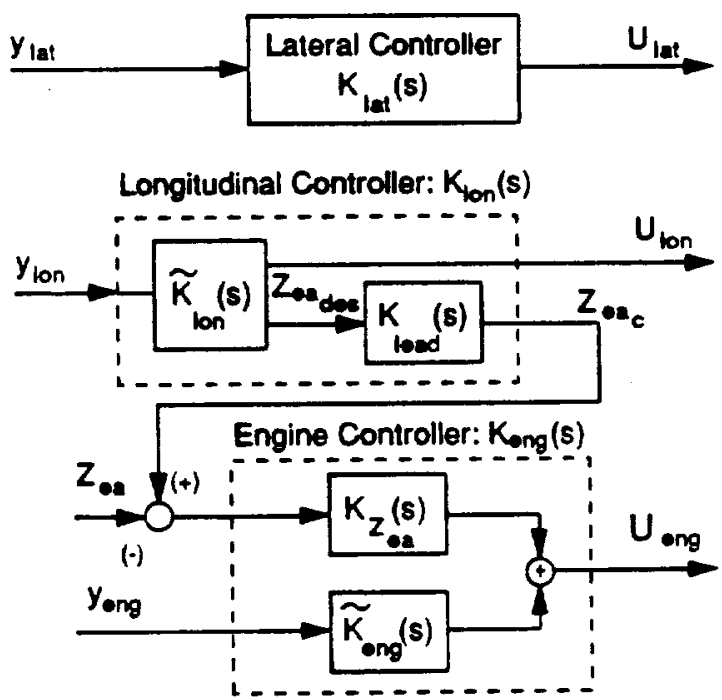

Figure 6. Partitioned Controller Structure 
Step 2:

Since the integrated models are derived about steady $\rightarrow$ tate level flight, there is very little coupling from the lateral controls $\overline{\mathbf{v}}_{\text {lat }}$ to longitudinal and propulsion bystem dynamic response. However, there is strong coupling from the engine controls $\overline{\mathrm{u}}_{\text {eng }}$ to the longitudinal response. Therefore the centralized controller $K(6)$ was first approximated by decoupled lateral and longitudinal-plus-engine subcontrollers i.e.

$$
K(s) \approx\left[\begin{array}{ll}
K_{\text {lat }}(s) & 0 \\
0 & K_{1+e^{(s)}}
\end{array}\right]
$$

with the lateral subcontroller $K_{\text {lat }}(s)$ such that

$$
\overline{\mathrm{u}}_{\text {lat }}(s)=\mathrm{K}_{\text {lat }}(s) \cdot \overline{\mathrm{y}}_{\text {lat }}(s)
$$

and the longitudinal-plus-engine subcontroller $\mathrm{K}_{\mathrm{l}}+\mathrm{e}^{(\mathrm{s})}$ such that

$$
\left[\begin{array}{l}
\bar{u}_{\text {lon }}(s) \\
\bar{u}_{\text {eng }}(s)
\end{array}\right]=K_{1+e^{(s)}} \cdot\left[\begin{array}{l}
\bar{y}_{\text {lon }}(s) \\
\bar{y}_{\text {eng }}(s)
\end{array}\right]
$$

State-space representations of the partitioned subcontrollers $K_{\text {lat }}(s)$ and $K_{1+e}(s)$ were obtained by reduced order approximations of the corresponding input/output portions of the 14th order centralized controller. Application of the internally balanced realization based controller reduction approach [13] resulted in a th order lateral subcontroller and a 10th order longitudinal-plus-engine subcontroller. The closed-loop performance, including the decoupling of the lateral and longitudinal responses, with this controller partitioning approximation compared very well with the performance obtained using the centralized controller.

Step $3:$

The portion of the engine subcontroller transfer function matrix from $\bar{y}_{\text {eng }}$ to $\bar{u}_{\text {eng }}, \bar{K}_{\text {eng }}(s)$ in Fig. 6, was obtained as a 4 th order approximation of the corresponding portion of the longitudinal-plus-engine subcontroller $K_{1+e^{(s)}}$ using internally balanced controller reduction. This $\dot{K}_{\text {eng }}(s)$ portion of the engine subcontroller approximates the fan speed command tracking, gross thrust regulation and bleed flow disturbance rejection properties of the centralized controller.

\section{Step 4}

The closed-loop gross thrust responses for the longitudinal-plus-engine system, using the $\mathrm{K}_{\mathrm{l}+\mathrm{e}}(\mathrm{s})$ subcontroller, were analyzed for longitudinal controlled variable commands to determine the requirements on thrust command ( $\bar{z}_{\text {ea }}$ ) tracking. This analysis indicated that tracking bandwidths of $4.5 \mathrm{rad} / \mathrm{s}$ for each of the three thrusts, FG9, FGE and FGV, would be adequate to maintain high level svstem performance with partitioned controllers. Using a mixed sensitivity $\mathrm{H}_{\alpha}$ formulation with the engine subsystem as the design plant, a controller was designed to provide decoupled command tracking of $\bar{z}_{\text {ea }}$ with fan speed regulation up to the desired bandwidths

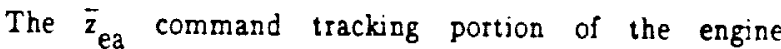
subcontroller, $K_{z}$ (s) in Fig. 6, was then obtained as a 3rd order approximation of the $\mathrm{H}_{0}$ controller. Note that this $K_{z_{e a}}$ (s) controller when combined with the $\bar{K}_{\text {eng }}(s)$ controller of Step 3 as shown in Fig. 6, results in an engine subcontroller which provides decoupled command tracking of fan speed and the three gross thrusts.

Step 5:

For the longitudinal-plus-engine subsystem, the $\overline{\mathrm{y}}_{\text {lon }} \rightarrow \overline{\mathrm{v}}_{\text {eng }}$ portion of the $\mathrm{K}_{\mathrm{l}+\mathrm{e}}{ }^{(\mathrm{s})}$ vubcontroller provides a desired response for the interface variables $\bar{z}_{e a}$ from the longitudinal controller inputs $\bar{y}_{\text {lon }}$ to be able to track the longitudina controlled variable commands. The transfer function matrix from the longitudinal controller inputs $\bar{y}_{\text {lon }}$ to the longitudinal controller outputs $\bar{u}_{\text {lon }}$ and the desired interface variable outputs $\bar{z}_{\text {ea des }}$ was obtained by considering the $\overline{\bar{y}}_{\text {eng }} \rightarrow \overline{\mathrm{v}}_{\text {eng }}$ loop closed as shown in Fig. 7.

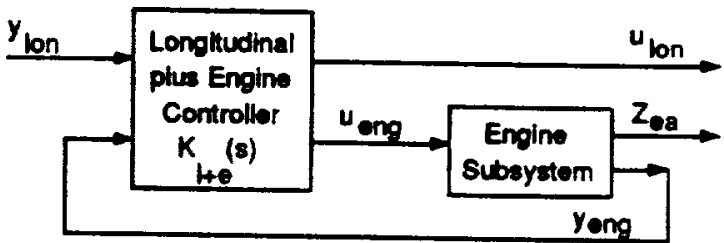

Figure 7. Block Diagram for Determining $\bar{K}_{\text {lon }}$ (s) Part of the Longitudinal Partitioned Controller

The $\dot{\mathbf{K}}_{\text {lon }}(8)$ portion of the longitudinal subcontroller, with the structure shown in Fig. 6, was then obtained as a 9th order approximation of this transfer function matrix.

Step 6:

Since the engine subcontroller provides limited bandwidth for $\bar{z}_{\text {ea }}$ command tracking, some lead compensation is needed on the $\bar{z}_{\text {ea }}$ ges gerated by the $\overline{\mathrm{K}}_{\text {lon }}(\mathrm{s})$ portion of the longitudinal controller in order to have $\bar{z}_{\text {ea }} \approx \bar{z}_{\text {ea des }}$ so as to be able to maintain the centralized control performance with the partitioned controllers. The lead compensation, $K_{\text {lead }}(s)$ in Fig. 6, was chosen to be of the form

$$
\begin{gathered}
K_{\text {lead }}(s)=\operatorname{diag}\left(K_{1}(s), K_{1}(s), K_{1}(s)\right), \\
\text { with } K_{1}(s)=\frac{8+4.5}{4.5} \cdot \frac{12}{s+12}
\end{gathered}
$$

resulting in an effective bandwidth of $12 \mathrm{rad} / \mathrm{s}$ in the $\bar{z}_{\text {ea des }} \bar{z}_{\bar{z}}$ ea responses

Extensive comparisons were made between the closed-loop system responses with the centralized controller and with the partitioned subcontrollers described above. An example comparison is shown in Figs 8 and 9 for a transient pitch rate and steady $\rightarrow$ tate pitch 


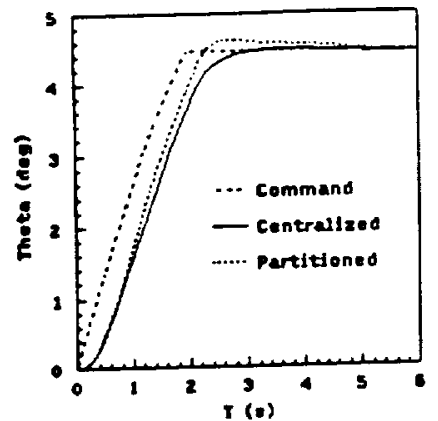

(a)

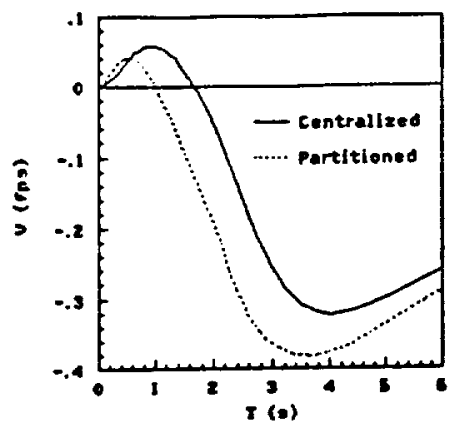

(b)

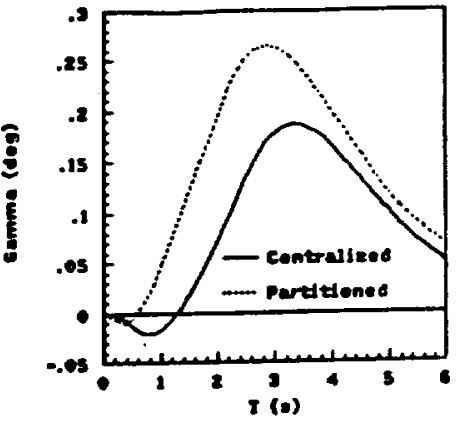

(c)

Figure 8. Comparion of Closed-Loop Response to Pitch Attitude Command $\left(\theta_{c}\right)$ with Centralized and Partitioned Controllers

attitude hold command. Fig. 8(a) shows the $\theta_{c}$ and the $\theta$ response with the centralized and partitioned controllers and Figs 8 (b) and (c) show the corresponding velocity (V) and fight path angle $(\gamma)$ response. There is a small degradation in pitch tracking and slight increase in velocity and flight path response coupling in going from centralized to partitioned controller. Similar small levels of performance degradation were observed for the other longitudinal commands while there was no noticeable degradation for the lateral commands.

Analyses of the gross thrust requirements to track the pitch command indicated large transient and steady-tate FG9 and FGE requirements with little change in FGV. Fig. 9 compares the response of the FG9 and FGE gross thrusts for the $\theta_{c}$ command with centralized controller and with partitioned controller. The FGE response with the partitioned controller is very close to that with the centralized controller and there is agreement between the FG9 responses also.

The parameter optimization approach of Ref. [12] can be applied to the partitioned subcontrollers developed berein to more closely match the performance with the centralized controller. However, the levels of performance degradation evident from the evaluation of the partitioned subcontrollers are quite small. Therefore it was decided to proceed with further development and evaluation of the IFPC design with these partitioned subcontrollers.

\section{Prefilter Design}

As mentioned earlier, it is desirable to provide decoupled control of the aircraft motion in the various axes from the pilot control effectors to reduce pilot workload in demanding tasks such as the decelerating approach to hover landing task being considered here. Typically, in an integrated control mode for the transition phase, the pilot would have independent control of pitch rate $(q)$, roll rate (p). sideslip angle $(\beta)$, acceleration along light path ( $(T)$ and flight path angle $(\gamma)$ through the longitudinal stick. lateral stick, rudder pedal, throttle and a thumb whe:" (either on the stick or the throttle assembly), respective] 14!. The "ideal response models" for response in each of these variables $\left(z_{i}\right)$ to pilot selected command $\left(z_{i_{\text {sel }}}\right)$ was chosen to be of the form

$$
\begin{gathered}
\frac{z_{i}}{z_{j_{\text {sel }}}}=\frac{\tau_{i} \omega_{i}^{2}\left(s+1 / \tau_{j}\right)}{s^{2}+2 \zeta \omega_{i} s+\omega_{i}^{2}} \\
\zeta=0.89, \omega_{i}=1.789 / t_{90_{i}} \text { and } \tau_{i}=0.625 \cdot t_{90_{i}}
\end{gathered}
$$

where $t_{90}$ is the desired $90 \%$ rise time for the controlled
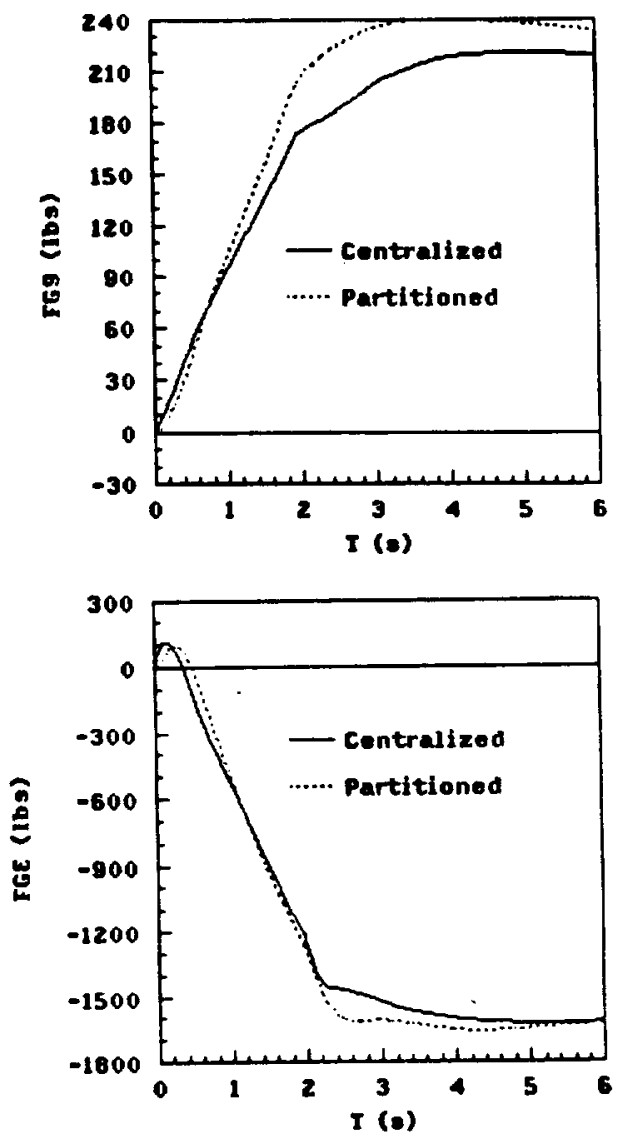

Figure 9. Gross Thrust Response to Pitch Attitude Command $\left(\theta_{c}\right)$ with Centralized and Partitioned Controllers

variable of interest. The above choice of the "ideal response model" results in fast response with little overshoot. The $t_{\theta 0_{i}}$ values for the 5 pilot controlled variables were selected based on Level I handling qualities requirements $[10,11]$ and are listed in Table 1.

The partitioned controller provides reasonable decoupling in the closed-loop response to commands, 80 only separate single-input single-output prefilters are only separate single-input to compensate for any deficiencies in the tracking needed to compensate command. Analyses of the closed-loop 
command tracking response with the partitioned controller indicated that simple prefilters of the form

$$
P_{i}(s)=\frac{s+a_{i}}{a_{i}} \cdot \frac{b_{i}}{s+b_{i}}
$$

providing lead compensation in the frequency region of desired bandwidth of control $\left(\omega_{i}\right)$ for each pilot commanded variable $\left(z_{j}\right)$ will be sufficient to "closely" match the ideal response models. The lead prefilter parameters used for this study are listed in Table 1. No lead compensation was needed for the roll rate because the response obtained with the feedback controller itself was suffuciently close to the desired response

An example comparison of the ideal response model and the closed-loop response achieved with the lead precompensation of Table 1 . for a pitch rate command is shown in Fig. 10. Acceleration (V) and roll rate (p) response comparisons also showed an excellent match between the desired and achieved responses. There was Bome discrepancy for the light path angle $(\gamma)$ and sideslip angle $(\not)$ responses in that the achieved responses had an initial response delay and an overshoot as compared to the ideal response. However, both the initial response delay and the overshoot appear to be small enough to not have any significant deterioration in the piloted system performance.

IFPC Evaluation

In order to evaluate the closed loop system response before going to a full nonlinear simulation, the configuration in Fig. 11 was established. This configuration is comprised of five major sections: pilot command shaping, the partitioned, hierarchical controller, engine fan speed schedule, engine limit logic, and model of the integrated plant which includes the ARCS to bleed flow demand nonlinearity. The command shaping block consists of the prefilters and blending to create $\mathrm{Vv}, \mathrm{Qv}$ and $P v$ commands from $V, q$ and $p$ commands. The partitioned, hierarchical controller consists of the lateral, longitudinal and engine subcontroljers with the input/output structures discussed in the previous section. For the current evaluation, the three gross thrusts.

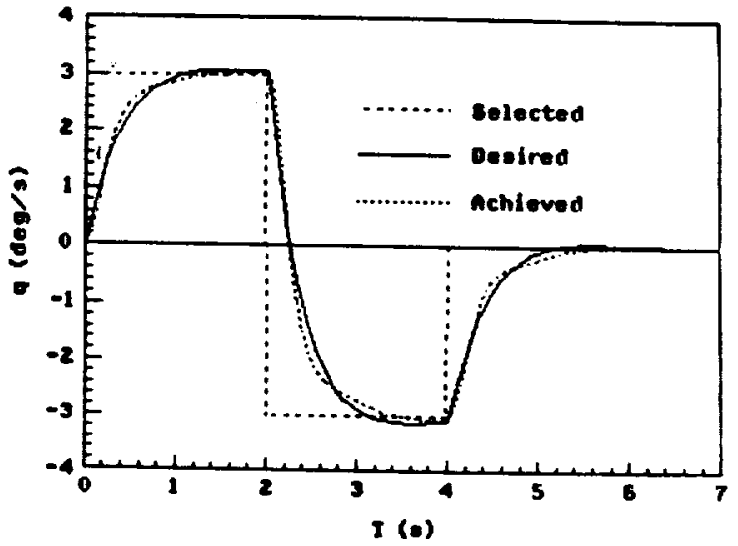

Figure 10. Pitch Rate (q) Response to Pilot Selected Command $\left(q_{\text {mel }}\right)$ - Ideal and Achieved with Partitioned Controlier and Lead Precompensation

elements of $\bar{z}_{\text {ea }}$, are assumed to be measured variables. The fan speed schedule generates a fan speed command as a function of the total gross thrust command, which is calculated based on the individual thrust commands $\left(\bar{z}_{e a}\right)$.

For this application, total gross thrust is defined relative to the aft nozale (i.e., it will be the thrust obtained if the total engine mass flow were to exit from the aft nozzle). The engine limit logic modifies the engine controller commands to the engine actuators based on whether limit condition exists. These modified actuator commands are passed on as $\bar{u}_{\text {eng }}$ to the integrated plant model.

The limit logic block protects the engine from temperature extremes and from exceeding the fan surge margin. The core engine temperstures (and other variables [15]) are limited by the acceleration/deceleration (accel/decel) schedule which limits the fuel fow as a function of high pressure compressor exit static pressure (PS3), the core rotor speed (N25) and the high pressure

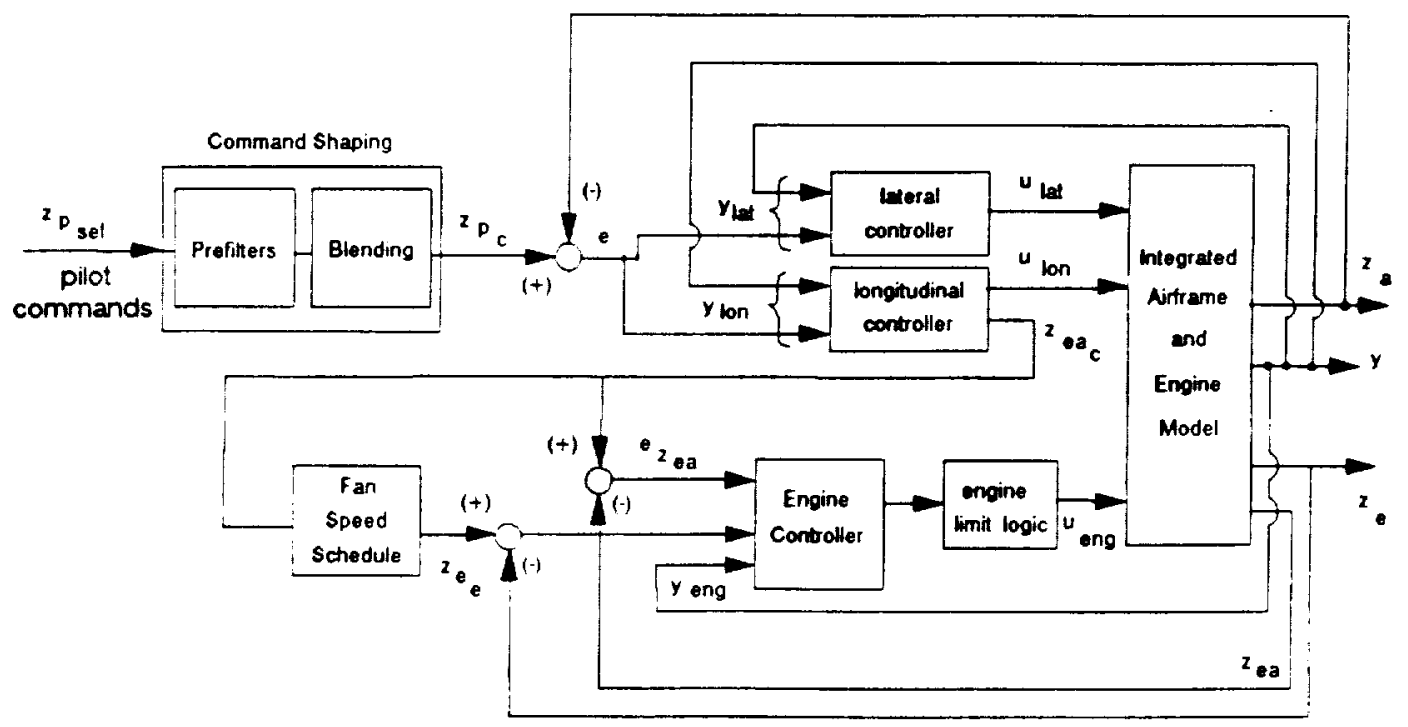

Figure 11. Block Diagram for Overall IFPC System Evaluation 
compressor inlet temperature (T25). The schedule variables required for the limit protection logic are not shown in Figure 11. For large, quick fuel flow transients, the accel/decel schedule constitutes an effective fuel flow rate limit [15]. The fan surge margin is insured to stay above a desired minimum value by limiting the minimum value of the ratio of a pressure difference to a static pressure measured at the inlet to the bypass duct, DP/P 15]. If $D P / P$ falls below the minimum value, then all areas commanded by the engine controller ( $A 8$, effective ejector area through ETA, and A78) are increased by multiplying the commanded area value by the following ratio:

$$
\frac{A T_{\text {min }}}{A T_{c}}
$$

where $A T_{\min }$ is the value of the minimum area necessary to maintain the DP/P limit value and $A T_{C}$ is the total area command which is calculated from the values generated by the linear controller for A8, ETA and A78. In the limit protection logic, $\mathrm{AT}_{\text {min }}$ is calculated by a tracking controller which maintains $D P / P$ above the minimum value. This limit protection scheme is consistent with known turbofan engine limit protection schemes [16].

Transient responses were obtained for pilot commands typical of the required maneuvering in the transition flight regime for all the five pilot controlled variables - V, $q, \gamma, p$ and $\beta$. All responses yielded acceptable closed-loop performance, in terms of closely matching the response of the ideal response models in the commanded variable with decoupling of the response in other variables, even though engine limits were encountered for pitch rate and flight path angle commands. A problem was encountered in the response to a step sideslip $(\beta)$ command. The propulsion system continued to operate on the surge protection limit. The controller commands steady roll and yaw RCS areas to track the steady sideslip command which results in a steady RCS bleed flow demand (WB3). The current engine fan speed schedule does not account for the disturbance effects of the steady-state RCS bleed flow demand and was commanding a decrease in the fan speed command, based on a decrease in gross thrust requirement, whereas the engine controller was simultaneously commanding an increase in the fuel flow (WF) to offset the bleed low disturbance effects. Modification of the fan speed schedule might be necessary to be able to perform steady sideslip maneuvers independent of roll at the low speeds in the transition envelope.

Of all the responses that were studied, the worst case requirement for total grose thrust was for a three degree increase in the flight path angle. The accel limit was briefly encountered during the transient response for the step flight path command and the engine was operating on the fan surge margin limit. The effect of engine limit operation for the flight path command is shown in Figs. 12 and 13 in terms of response of various shown in Figs. 12 and 13 in and without limit protection (L.P.). The light path response with and without L.P., shown in Fig 12 (a), are very close although both have an overshoot as compared to the ideal response. The response of the other longitudinal variables, $\theta$ and $V$, from the flight of the other longitudinal variables, and the engine limit operation as shown in Figs. 12(b) and (c). Fig. 13(a) shows operation as shown in actuator value) corresponding to the flight path angle command. Note that the two responses, with and without limit protection, have similar characteristics although the effective valve angle is slightly increased with limit protection because the DP/P limit protection scheme increases all the nozzle areas to maintain minimum surge increases all the nozzle areating point for this evaluation is very close to the minimum required fan surge margin and a decrease of approximately $1 \%$ from a nominal value of a decrease of approxmately $15 \%$ is all that can be tolerated. Fig. 13 (b) shows that the minimum required surge margin limit is violated without the limit protection while the limit protection keeps the the lo minimum safety limit except for the initial transient during mode switching. Finally, Fig.

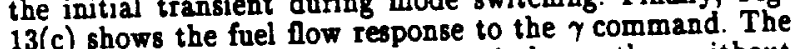
fuel fow with the limit protection is lower than without fuel tow with the limit protection because the engine is operating on the limit protection limit and is not tracking the fan speed command generated from the fan speed schedule Although, it is not apparent from the figure, the accel limit for fuel flow was encountered for the brief period from 0.4 to 0.8 secs. This series of figures shows that the linear partitioned controller maintain the desired aircraft performance even when the engine operation is limited by a safety limit.

\section{Table 1. Ideal Response Medel Rise Time and Prefilter Lead Compensation}

\begin{tabular}{|c|c|c|c|}
\hline Variable $\left(\mathbf{z}_{\mathrm{i}}\right)$ & $t_{90}$ & $\underline{a_{i}}$ & $\underline{b_{i}}$ \\
\hline $\begin{array}{l}V \\
q \\
\gamma \\
p \\
\beta\end{array}$ & $\begin{array}{l}2.0 \\
0.8 \\
3.0 \\
1.2 \\
1.8\end{array}$ & $\begin{array}{c}0.7 \\
4 \\
0.5 \\
\overline{2}\end{array}$ & $\begin{array}{l}1 \\
8 \\
1 \\
4\end{array}$ \\
\hline
\end{tabular}

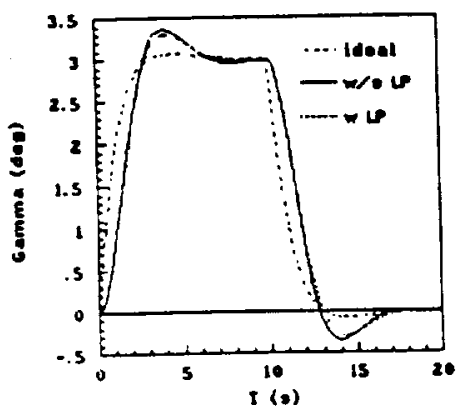

(a)

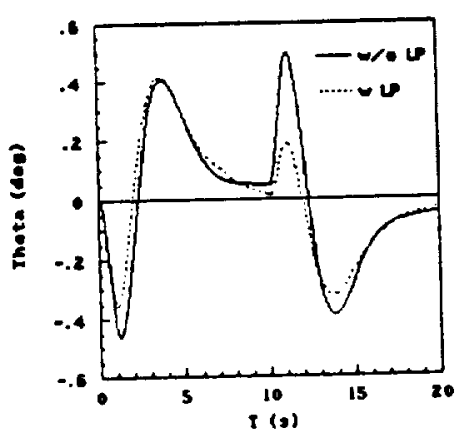

(b)

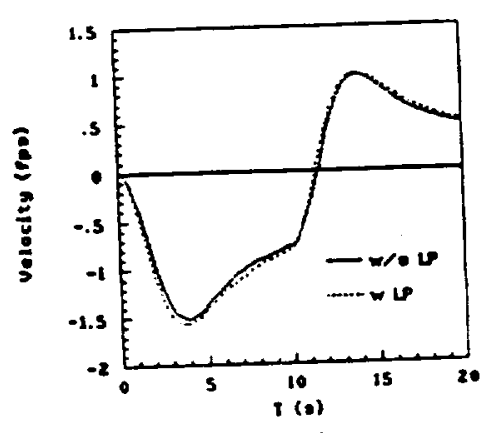

(c)

Figure 12. IFPC System Response to Step Pilot Commanded Flight Path Angle $\left(\gamma_{\text {sel }}=3\right.$ deg) - with and without Limit Protection (LP) 


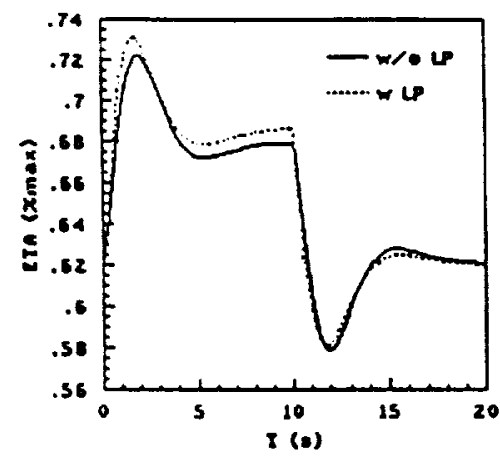

(a)

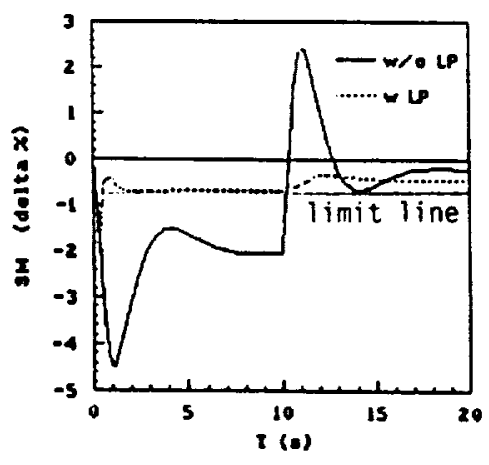

(b)

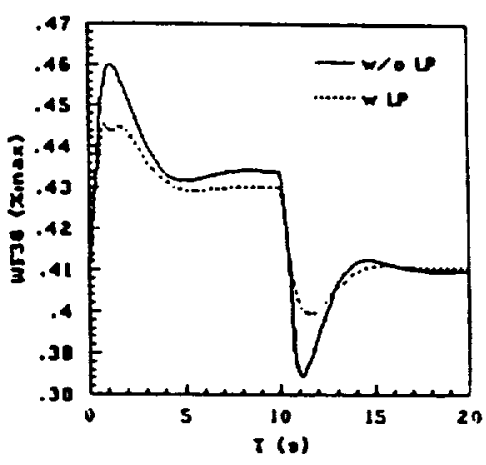

(c)

Figure 13. IFPC System Ejector Butterly Valve Angle (ETA), Fan Surge Margin (SM), and Fuel Flow (WF) Requirement for Step Pilot Commanded Flight Path Angle $\left(\gamma_{\mathrm{sel}}=3\right.$ deg)

\section{Conclusion}

The Integrated Flight/Propulsion Control (IFPC) system presented in this paper demonstrates the major steps in the linear control design portion of an IFPC design methodology which is currently under development. Application of these steps is shown to result in "simple", easy to implement, highly structured controllers that provide decoupled response to various pilot control effector inputs with response characteristics that meet Level I handling qualities requirements. The evaluation results also indicate that the desired linear system performance characteristics are maintained even when the propulsion system operating fan speed schedule and safety and limit logic (such as surge protection and acceleration/deceleration schedule) are included in the closed-loop evalustion system. Controller scheduling is currently being developed to extend the operation of the aircraft over the transition flight envelope using the IFPC design presented in this paper as the baseline transition phase control design. Once the scheduling is complete, it is planned to evaluate the IFPC design in a fxed-base piloted simulation.

\section{References}

1] Garg, S., Ouzts, P., Lorenzo, C.F., and Mattern, D.L., "IMPAC - an Integrated Methodology for Propulsion and Airframe Control," 1991 American Control Conference, Boston, MA, June 1991.

[2] Garg, S., Mattern, D.L., and Bullard, R.E., 'Integrated Flight/Propulsion Control System Design

Based on a Centralized Approach," Journal of Guidance, Control and Dynamics, Vol. 14, No. 1, Jan.-Feb. 1991, pp. 107-116.

3] Mattern, D.L., Garg, S., and Bullard, R.E., "Integrated Flight/Propulsion Control System Design Based on a Decentralized, Hierarchical Approach," AlAA Paper 89-3519, Guidance, Navigation and Control Conference, Boston, MA, August 1989.

[4] Garg, S., Ouzts, P., "Integrated Flight/Propulsion Control Design for a STOVL Aircraft Using B-Infinity Control Design Techniques," 1991 American Control Conference, Boston, MA, June 1991.

(5) Garg, S., Mattern, D.L., Bright, M., and Ouzts, P. "B-Infinity Based Integrated Flight/Propulsion Control Design for a STOVL Aircraft in Transition Flight," AlAA Paper 90-3335, Guidance, Navigation and Control Conference, Portland, OR, August 1990.
[6] Akhter, M.M., Vincent, J.H., Berg, D.F., and Bodden, D.S., "Simulation Development for US/Canada Control Technology Program," Proceedings of the Twentieth Annual Modeling and Simulation Conference, University of Pittsburgh, Pittsburgh, PA, June 1989.

[7] Drummond, C.K., and Ouzts, P., "Real-time Simulation of an F110/STOVL Turbofan Engine," NASA TM-102049, Oct. 1989.

(B) Doyle, J.C., Glover, K., Khargonekar, P.P., and Francis, B.A., "State-Space Solutions to Standard $\mathrm{H}_{2}$ and $\mathrm{H}_{\text {w }}$ Control Problems," IEEE Transections on Automatic Control, Vo. 34, No. 8, Aug. 1989, pp. 831-847.

[9] "MATRIXx Robust Control Module - User's Guide," Integrated Systems Inc., Santa Clara, CA, October 1989.

[10] "Military Specification - Flying Qualities of Piloted V/STOL Aircraft," MIL-F-83300, Wright Patterson AFB, OH, December 1970.

(11) Hoh, R.H., and Mitchell, D.G., "Proposed Revisions to MIL-F -83300 V/STOL Flying Qualities Specifications," NADC-82146-60, Naval Air Development Center, Warminster, PA, January 1986.

[12] Schmidt, P., and Garg, S., "Decentralized Hierarchical Partitioning of Centralized Integrated Controllers," 1991 American Control Conference, Boston, MA, June 1991 .

[13] Moore, B.C., "Principal Component Analysis in tinear Systems: Controllability, Observability and Model Reduction," IEEE Trans. on Automatic Control, Vol. AC-26, Feb. 1981, pp. 17-31.

[14] "E-7D Flight Control System Description," Systems Control Technology, Palo Alto, CA, May 1990. Report prepared for GE Aircraft Engines under Contract No. 200-14-14P94337.

[15] Mattern, D., and Ouzts, P., "A Linear Control Design Structure to Maintain Loop Properties During Limit Operation in a Multi-Nozzle Turbo Fan Engine," AIAA Paper 91-1997, 27th Joint Propulsion Conference, Sacramento, CA, June 1991.

[16] Soeder, J.F., "F-100 Multivariable Control Synthesis Program," NASA TP 2231, Oct. 1983. 


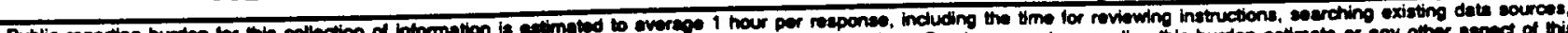

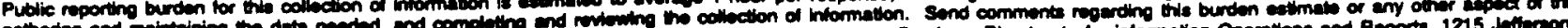

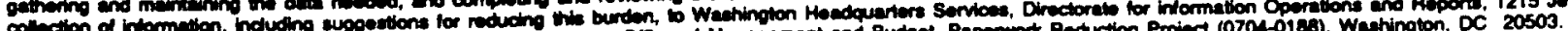

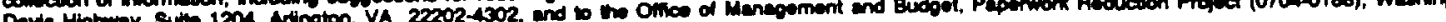
\begin{tabular}{l|l|l|l|l|}
\hline A. REPOAT TYPE ANO DATES COVERED & 2. AEPOAT DATE
\end{tabular}

\begin{tabular}{l|l|l|} 
1. AGENCY USE ONLY (Leave blan') & 2. AEPOAT DATE & Technical Memorandum
\end{tabular}

4. TILE AND SUBTITLE

Application of an Integrated Flight/Propulsion Control Design Methodology to a STOVL Aircraft

6. AUTHOR(B)

Sanjay Garg and Duane L. Mattern

\section{PERFORIINO OROANRATION NAME(S) AND ADORESSES)}

National Aeronautics and Space Administration

Lewis Research Center

Cleveland, Ohio 44135-3191

9. SPONSOAINOMONTORINO AOENCY NAMES(S) AND ADDRESS(ES)

National Aeronautics and Space Administration

Washington, D.C. 20546-0001
5. FUNDING NUMBERS

WU - 505- $62-50$

- PEAFOAMING OAGANIZATION REPORT NUMBER

$E-6583$

11. SUPPLEMENTAAY NOTES Prepared for the Guidance, Navigation and Control Conference sponsored by the American Institute of Aeronautics and Astronautics, New Orleans, Louisiana, August $12-14,1991$. Sanjay Garg, NASA Lewis Research Center, Duane L. Mattem, Sverdrup Technology, Inc., Lewis Research Center Group, 2001 Aerospace Parkway, Brook Park, Ohio 44142. Responsible person, Sanjay Garg, (216) 433 - 2355 .

12.. DISTAIBUTION/AVAILABILTTY STATEMENT 12b. DISTRIBUTION CODE

Unclassified - Unlimited

Subject Categories 08 and 63

10. SPONSOAING/MONITORINC AOENCY REPORT NUMBER

NASA TM - 105254

AIAA - 91 - 2792

\section{ABstract (Meximum 200 wonds)}

Results are presented from the application of an emerging Integrated Flight/Propulsion Control (IFPC) design methodology to a Short Take-Off and Vertical Landing (STOVL) aircraft in transition flight. The steps in the methodology consist of designing a centralized controller, partitioning the centralized controller into separate subsystem controllers and designing command shaping prefilters to provide the overall desired response to pilot command inputs. A previously designed centralized controller is first validated for the integrated airframe/engine plant used in this study. This integrated plant is derived from a different model of the engine subsystem than the one used for the centralized controller design. The centralized controller is then partitioned in a decentralized, hierarchical structure comprising of airframe lateral and longitudinal subcontrollers and an engine subcontroller. Command shaping prefilters from the pilot control effector inputs are then designed and time histories of the closed-loop IFPC system response to simulated pilot commands are compared to desired responses based on handling qualities requirements. Finally, the propulsion system safety and nonlinear limit protection logic is "wrapped" around the engine subcontroller and the response of the closedloop integrated system is evaluated for transients that encounter the propulsion surge margin limit.

\section{SUBJECT TERMS}

Integrated flight propulsion control; Short take-off vertical landing aircraft; Controller partitioning; Propulsion system limits

15. NUMBEA OF PAOES 12

SECUATY CLASSIFICATION OF REPOAT

Unclassified

18. SECUAITY CLASSIFICATION
OF THIS PAOE
Unclassified

Unclassified
19. SECUATY CLASSIFICATION

OF ABSTRACT

Unclassified 


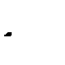


National Aeronautics and

Space Administration

Lewis Research Center

Cleveland, Ohio $\mathbf{4 4 1 3 5}$

Oritelal Bualnewa

Penetry for Prtvete Unes 2000
FOUATH CLASS MAL

ADDAESS CORAECTION REOUESTED

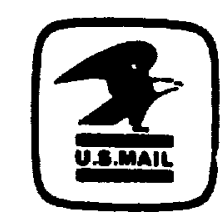

Poslage and Fees Paid National Aeronaulics and Space Administration NASA 45 ? 